\title{
ИДЕНТИФИКАЦИЯ ФУНКЦИОНАЛЬНОЙ РОЛИ ИНСТИТУТОВ ФОРМИРОВАНИЯ СТРУКТУРЫ ЭКОНОМИЧЕСКОГО ПРОСТРАНСТВА РЕГИОНОВ
}

\author{
(c) 2018 Кетова Наталья Петровна \\ заслуженный деятель науки РФ, доктор экономических наук, профессор \\ зав. кафедрой «Маркетинг и коммуникации в бизнесе» \\ Южный федеральный университет \\ 344002, г. Ростов -на-Дону, ул. М. Горького, 88 \\ E-mail:kmik2012@mail.ru \\ (c) 2018 Колесников Юрий Семёнович \\ заслуженный работник высшей школы РФ \\ доктор экономических наук, профессор, главный научный сотрудник \\ Южный федеральный университет \\ 344002, г. Ростов -на-Дону, ул. М. Горького, 88 \\ E-mail: kolesnickov.ju@mail.ru \\ (c) 2018 Овчинников Виктор Николаевич \\ заслуженный деятель науки РФ, доктор экономических наук, профессор, \\ профессор-консультант кафедры управления развитием пространственно-экономических систем \\ Южный федеральный университет \\ 344002, г. Ростов -на-Дону, ул. М. Горького, 88 \\ E-mail: ovn@aaanet.ru
}

В статье представлены результаты разработки проблемы выявления воздействия институтов различной природы на структурную организацию экономического пространства регионов Юга России, идентификации их функциональных ролей и позиций в этом формообразующем процессе.

Ключевые слова: экономическое пространство региона, структурная организация, типологические признаки, морфология, формообразование, экономический каркас региона, социиохозяйственный уклад, технологический уклад.

Морфология экономического пространства региона предполагает исследование процесса формообразования его структурных элементов (структурирующих его компонентов, составляющих) на мезоуровне иерархической организации экономической системы, т.е. в формате мезоэкономических звеньев ее таксономии.

Поскольку экономика является многосложной иерархически организованной системой, то и типологические признаки и подходы к изучению формообразующих элементов ее пространственно-структурной организации должны быть многокритериальными, многомерными. Действительно, внутрирегиональные формы структурно-компонентной организации экономического пространства можно изучать с позиции структурно-уровневого подхода идентификации экономических пространств функционирования субординированной системы субъектов рыночного хозяйства региона [1, с.74-78].
Единичный представитель социума и актор экономической деятельности - человек-индивид функционирует в формате структурно-уровневого звена наноэкономического формообразования внутрирегионального экономического пространства.

Домохозяйство как первичная (семейная) ячейка социума и полноправный рыночный (или полунатурально-рыночный) субъект региональной хозяйственной системы формирует номоэкономическую форму структурно-уровневой организации экономического пространства региона.

Интроэкономическая форма (ступень) структурно-уровневой его организации представлена пространственным форматом функционирования субъектов структурных подразделений внутрикорпорптивных структур (компаний, фирм), включенных в контур связей производственно-хозяйственной организации, ее деятельно- 
сти как единой структурной единицы рыночного хозяйства.

Формат микроэкономического уровня структурной таксономии экономического пространства региона представлен полем рыночного взаимодействия разномасштабных субъектов экономической деятельности: индивидов, домашних хозяйств, корпоративных бизнес-структур на локальном рынке, спрос и предложение на котором формируется силами рыночного притяжения и конкурентного противостояния агентов рыночной экономики.

Собственно, мезоформат экономического пространства региональной экономики персонифицированно представлен его совокупным субъектом хозяйствования и социальной жизни, включающем население, в том числе, субъектов бизнес-среды, органы власти и хозяйственного управления, а также институты гражданского общества регионального социума.

Далее следуют: макроуровень - национальной и мегауровень - мировой экономики.

Однако, это - схематический пример реализации только одного субъектно-уровневого подхода к анализу процессов формообразования и структурной организации морфологии регионального экономического пространства.

Другими, не менее плодотворными подходами, могут быть аспекты изучения формообразующих процессов в экономическом пространстве региона с позиции идентификации в нем подпространств функционирования различных социохозяйственных секторов: полунатурально-этноэкономического, мелкотоварного, корпоративного и государственного [2, с.7-23]. Также конструктивной представляется позиция изучения морфологии экономического пространства региона с использованием принципа таксономии (подхода) по критерию технологических укладов, определяющих технико-технологический строй производства: архаично-традиционный, ремесленный, индустриальный (с этапом неоиндустриализации), постиндустриальный.

Важным признаком таксономии экономического пространства региона является экосистемный подход, позволяющий выделить ареалы относительно целостных локальных экосистем, характеризуемых типом хозяйственного природопользования и режимом природосбережения, детерминирующих свойства ноосферы как среды жизнедеятельности населения соответствующих субрегиональных природохозяйственных подсистем с позиции императива её экологичности [3, с.356-361].

С этих позиций, методологически важным ключом является выделение экоприродохозяйственных подсистем экономического пространства региона по критерию формирования речных бассейнов. Этот подход представляется конструктивным, поскольку позволяет, во-первых, проследить исторический процесс и схему хозяйственного освоения территории региона в зависимости от его гидрологической сети; во-вторых, учесть все виды загрязнений литосферы, гидросферы и атмосферы в формате речного бассейна; в-третьих, разработать и внедрить единую систему мониторинга состояния всех сред в формате речного бассейна и в-четвёртых, выработать систему мер единой природохозяйственной и природоохранной политики.

Такой подход чрезвычайно важен для регионов Юга России, имеющих большие площади предгорных и горных территорий, разделённых горными хребтами, с речными долинами, формирующими пространства (подсистемы) активной природохозяйственной деятельности.

Этот методологический ключ даёт возможность выделения в регионах субрегиональных экосистем со специфической функциональной ориентацией: Азово-Черноморское побережье Краснодарского края - курортно-рекреационная экоподсистема региона, что можно сказать и о субрегионе Кавказских Минеральных Вод Ставропольского края.

Общий признак таксономии такого деления экономического пространства региона - определяющее влияние на формирование локальных экосистем акваторий морей, рек или обилие (наряду с развитой гидрологической сетью) многочисленных источников лечебных минеральных вод в недрах субрегиональных ареалов.

Чрезвычайно важным фактором формирования регионального рыночно-экономического пространства является объективное воздействие на его морфологию сил рыночного притяжения активной хозяйственной деятельности к ядрам многополярной структуры экономического каркаса региона.

Действительно, формирующиеся на базе крупномасштабных производственных структур (корпораций, компаний, предприятий) региона профильные специализированно-отраслевые оптовые рынки являются центрами притяжения, активизирующими хозяйственную деятель- 
ность, создающие зоны флуктуационного уплотнения рыночно-экономического пространства, формирующими выпуклости его рельефа. Они, как бы, «стягивают» рыночно-экономическое пространство региона в своеобразные «узлы» хозяйственной активности.

Поскольку в экономическом пространстве региона таких специализированных оптовых рынков, как правило, несколько, постольку они и формируют силами своего притяжения ресурсов, экономической активности, денежных потоков, логистических центров, транспортных интермодулей и т.д. « узловую» структуру экономического пространства региона. Например, в Ростовской области такими производственными центрами, «ядрами», формирующими многополярную структуру экономического каркаса региона являются: «Ростсельмаш», «Роствертол», Новочеркасский электровозостроительный завод, «Глория Джинс» и др. крупномасштабные специализированные компании, обеспечивающие рыночное предложение востребованной в России и за границей продукции.

На физико-географической карте, дополненной экономической координатой (третьим измерением по оси осциллят) такая трёхмерная картина (в формате 3D) могла бы выглядеть как рельефное изображение экономического пространства региона с выпуклостями (возвышениями, всхолмлениями) в соответствующих узловых точках географических координат предприятий-производителей. Будучи окрашенными в разные цвета, соответственно их производственной специализации, они, формировали бы радужную картину пространственных зон своего притяжения, представляющих рыночно специализированные подсистемы единого экономического пространства региона.

С позиции эконометрии, высота таких рельефных всхолмлений должна соответствовать производственно-рыночному потенциалу предприятия, формирующего рыночное предложение на профильно-специализированном оптовом рынке региона, а пространственные характеристики (параметры) охвата силами рыночного притяжения соответствующего подпространства, определяется величиной радиуса окружности, адеватной ёмкости данного оптового рынка.

Организованная, таким образом, структура рыночно-экономического пространства региона представляет собой совокупность пе- рекрывающих друг друга рыночно-целевых концентрических подсистем (подпространств), сформированных силами рыночного притяжения к производственно-коммерческим центрам (ядрам) специализированных и целеориентированных региональных оптовых рынков.

Из этого можно сделать вывод о том, что рынки представляют собой консистентные ядра хозяйственной матрицы экономического пространства региона, формирующие векторы центростремительного притяжения коммерческой деятельности к этим локальным узлам трансакционной активности как опорным точкам экономического каркаса региона

В регионах Юга России, особенно, республиках Южного и Северо-Кавказского федеральных округов, сохраняющих значительный удельный вес этноэкономического социохозяйственного сектора (уклада) в их хозяйственной структуре, существенную роль в формировании морфологии экономического пространства выполняют этнорынки.

Этнорынки представляют собой специфический вид рынков. Их отличительными чертами являются:

- чёткая ориентация на спрос двух основных целевых аудиторий потребителей: внутренних (население укоренённого этноса) и внешних (субъектов рекреации и туризма, интересующихся изделиями уникальных народных промыслов с этнонациональной символикой);

- специализация на реализации товаров потребительского назначения;

- локализация (дислокация) в территориальных ареалах проживания доминирующих коренных этносов.

Ориентация на целевые аудитории потребителей, как указывалось выше, имеет два доминантных вектора её реализации.

Первый из них направлен на удовлетворение специфических этнотрадиционных потребностей коренного населения в пище 9мясные продукты особого приготовления - «халяль» -, исключающие потребление свинины), в одежде (доминация тканей зелёного - цвет ислама и чёрного цвета - следование традициям долговременного траура по умершим членам многолюдных родовых общин), а также в изделиях для быта из кожи, пуха, шерсти, ковры, пледы, кардиганы, тёплые носки, варежки и др., необходимые в суровых климатических условиях горных и предгорных территорий. 
Второй вектор такой этнорыночной ориентации направлен на удовлетворение потребностей рекреантов и туристов в сувенирной продукции с этнонациональной символикой (изделия из металла, чеканка, продукция ювелиров с брендами: «Кубачи» в Дагестане, «Асия Еутых» в Адыгее и др.), а также их спроса на изделия этнопроизводства бытового назначения (из меха, кожи, пуха, шерсти, дерева).

Вторая особенность этнорынков тесно связана с первой. Это - специализация их на реализации товаров непроизводственного (потребительского) назначения: ориентация на непосредственное удовлетворение спроса конечного потребителя - человека, независимо то места его проживания (резидента или нерезидента данного этнотерриториального локадитета).

Третья отличительная черта этнорынков, также детерминированная первой, - «привязка» к территории компактного проживания доминирующего этноса силами рыночного притяжения, формирующая экономическое подпространство соответствующего этнорынка в морфологии экономического пространства региона.

Таким образом, результаты исследования функции этнорынков в формировании структуры экономического пространства регионов Юга России в целом, позволяет резюмировать их следующим образом.

1. Современные рынки представляют собой консистентные ядра хозяйственной матрицы экономического пространства региона, формирующие векторы притяжения коммерческой деятельности к этим локальным узлам рыночной активности, как опорным точкам экономического каркаса региона. Оценивая «ландшафт» имеющихся исследований, можно сделать заключение о том, что это - относительно новая, претендующая на самостоятельную область знаний, важнейшая сфера экономики, маркетинговых исследований, регионалистики.

2. Изучение вопросов устойчивости наличия этнокультурной составляющей в потреби- тельском спросе покупателей, проживающих в республиках Северного Кавказа, показало их очевидность. Особенно это присуще территориям, где локально проживает население, имеющее устойчивую приверженность к определенным продуктам питания, видам и цвету одежды. Данная тенденция отчетливо проявляется, например, при потреблении мясомолочных продуктов, в частности, в регионах проживания населения, исповедующего ислам, иудаизм, буддизм. Это актуализирует вопросы ориентации этнорынков регионов, например, Юга России на удовлетворение спроса целевых аудиторий потребителей

3. Проведенный анализ показал, что производители и поставщики продуктов питания чаще всего действуют в мультинациональной среде, в которой сильны локальные факторы, при существенной глобальной интеграции. Ключевым фактором успеха на таких рынках является адаптация производителей к местным условиям, учет вкусов и потребностей покупателей, во многом предопределяемых конкретной этнокультурной составляющей.

4. Оценка позиционирования этнорынков в структуре рыночно-экономического пространства регионов Юга России показала, что такого рода рынки повышают возможности локализации трудовой активности коммерческой деятельности, в т.ч. в этноориентированном малом бизнесе, приближения его к локальным узлам трансакционной активности, стимулируя их ориентацию на удовлетворение спроса целевых аудиторий населения конкретных регионов. Признание их специфики предполагает учет таких особенностей в моделях поведения компаний, ориентированных на максимальное удовлетворение покупательского спроса и повышение конкурентоспособности.

Статья подготовлена при поддержке гранта РФФИ (проект 18-010-00283 «Морфология экономического пространства региона: междисциплинарный подход»)

\section{Библиографический список}

1. Кетова Н.П., Овчинников В.Н. Структурно-уровневый подход к идентификации субординированной системы экономических пространств функционирования субъектов рыночного хозяйства // Phenomenon of the Market Economy: Vectors and Features Eevolution. Academic Monograph / Under the editorship of Sidorov. V.A., Yadgarov Ya. S., Chaplya V.V. London: LSP. Pp. 74-78. 
2. Овчинников В.Н. Трансформационные тенденции в развитии пространственно-экономической системы России и её регионов // Пространственное развитие экономических систем: структурные элементы, инструменты управления, возможности реализации экономической политики. Коллективная монография. Ростов-на-Дону: Издательство ЮФУ, 2015. С. 7-23.

3. Овчинников В.Н., Кетова Н.П. Природохозяйственные императивы структурной организации экономического пространства региона // Экономика и предпринимательство. 2018. №9. С. 356-361.

Поступила в редакцию 15.10.2018 